\title{
Carnitine palmitoyl transferase II deficiency, severe infantile form
}

INSERM

\section{Source}

INSERM. (1999). Orphanet: an online rare disease and orphan drug data base. Carnitine palmitoyl transferase // deficiency, severe infantile form. ORPHA:228305

The severe infantile form of carnitine palmitoyltransferase II (CPT II) deficiency (see this term), an inherited disorder that affects mitochondrial oxidation of long chain fatty acids (LCFA), is the early-onset form of the disease. 